\title{
AIRWAY WARMING IN ACCIDENTAL HYPOTHERMIA
}

\author{
E. LI. Lloyd, M.B., M.R.C.P.E., F.F.A.R.C.S. \\ Senior Registrar, Dept., of Anaesthetics, Royal Infirmary, Edinburgh
}

Accidental hypothermia is a hazard of many outdoor activities and the physiological changes, symptoms, signs and preventive precautions have been covered elsewhere. (Burton and Edholm, 1955; Freeman and Pugh, 1969; Keatinge, 1969; Taylor, 1972). However accidental hypothermia is a particular hazard of water activities since if the water temperature is below $20^{\circ} \mathrm{C}$ hypothermia is almost inevitable, the time of onset varying with a number of factors including the water temperature (Keatinge, 1969). Since it is unlikely that any water around or within the British Isles is ever above $20^{\circ} \mathrm{C}$, the hazard is ever present.

The methods of treatment at present available are::-

1. When found. Insulate the body and head to prevent further heat loss and allow spontaneous rewarming from the intrinsic metabolic heat (Taylor, 1972).

2. At base. Immersion in a hot bath, though this can only reduce the after-drop of core temperature at all if it is given within about 20 minutes of rescue from the water (Keatinge, 1969).

3. In hospital. A variety of sophisticated methods of core rewarming e.g., extra-corporeal circulation (Lloyd et. al., 1972) or relying on continued body insulation (Duguid, Simpson and Stowers, 1961).

People who become acutely hypothermic on the hills or in water are usually some distance from even small hospitals with the result that, by the time the victims have been admitted most have either rewarmed spontaneously or died. It is probable that most cases which are still hypothermic when they reach a hospital large enough to have the sophisticated equipment, are suffering from chronic hypothermia or have drug depressed metabolism. Any attempt to improve the situation should ideally therefore be applicable as soon as the victim is found.

Shivering and vigorous activity may raise the normal man's metabolic rate from a basal $100 \mathrm{~K} \mathrm{cal} / \mathrm{hr}$ to $500 \mathrm{~K}$ $\mathrm{cal} / \mathrm{hr}$, but the heat loss from the body surface may easily reach $2000 \mathrm{~K} \mathrm{cal} / \mathrm{hr}$ (Burton and Edholm, 1955), if the protective effect of the clothing is impaired, for example, the person on the hills who becomes soaked then becomes hypothermic.

When rescue procedures are started heat loss from the surface is reduced as much as possible by total insulation of the body including the head. In the ideal situation this means that the only remaining heat loss is by respiration. With an air temperature of $0^{\circ} \mathrm{C}$ it has been calculated that a man is losing $6.16 \mathrm{~K} \mathrm{cal} / \mathrm{hr}$ as direct heat loss through warming the inspired air and $14.78 \mathrm{~K}$ $\mathrm{cal} / \mathrm{hr}$ through loss of water vapour - a total of $20.94 \mathrm{~K}$ $\mathrm{cal} / \mathrm{hr}$ (Edholm and Bacharach, 1965). If the victim's core temperature is $30^{\circ} \mathrm{C}$ his basal metabolic heat production has been halved (Bigelour et. al., 1950) to $50 \mathrm{~K}$ $\mathrm{cal} / \mathrm{hr}$ and with a respiratory heat loss of approximately $20 \mathrm{~K} \mathrm{cal} / \mathrm{hr}$ there is only $30 \mathrm{~K} \mathrm{cal} / \mathrm{hr}$ to rewarm the person and counteract any deficiencies in the surface insulation. If therefore the respiratory heat and moisture loss can be prevented there is an immediate increase of available heat from $30 \mathrm{~K} \mathrm{cal} / \mathrm{hr}$ to $50 \mathrm{~K} \mathrm{cal} / \mathrm{hr}$. To produce this effect the victim should breathe a humidified atmosphere at a temperature equal to his core. If the temperature of the inspired humidified air is above that of the core, there is a bonus of additional heat and moisture.

These above facts are theoretical calculations and to test the idea in practice anaesthetised sheep were cooled by immersion in cold water and then rewarmed (Lloyd, Mitchell and Williams). The rate of rewarming achieved by insulating the body surface and supplying warm humidified air to breathe was three times greater than that achieved by surface insulation alone. Since these experiments were on anaesthetised sheep the results cannot be related directly to non-anaesthetised men. When the method has been used in human hypothermia cases however the results are encouraging (Lloyd 1973).

The cases treated were in hospital and are therefore not directly applicable to the outdoor situation in that they were mainly elderly, and therefore probably suffering from chronic hypothermia, or had taken drug overdoses. Fig. 1 shows the changes in a 55 year old man found lying in his room a few hours after taking an overdose of Largactil. Treatment was by wrapping him in blankets in a hot room and, since he was not breathing adequately, ventilation was assisted. By replacing dry gas ventilation with warmed humidified gas, a zero rate of warming, which had been static for three hours, was converted to a temperature rise. After three hours active warming was discontinued and the temperature continued to rise and showed the characteristic overshoot. The interesting comparison is that during the three hours active warming was used the core temperature rose $3^{\circ} \mathrm{C}$ whereas the next $3^{\circ} \mathrm{C}$ without airway warming required six hours. 


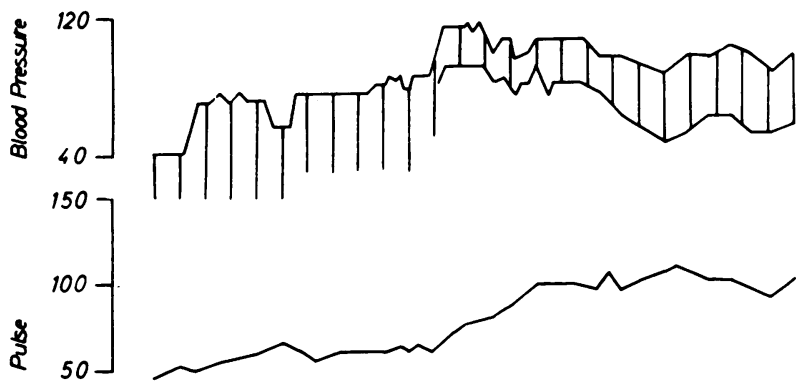

Fig. 2 shows the progress of a younger woman with a severe overdose of drugs. The metabolism was so depressed by the drugs that she was unable to rewarm spontaneously despite being wrapped in blankets. The introduction of airway warming on two occasions caused the core temperature to rise and on each occasion the rise stopped when the airway warming stopped. When the patient was first seen there were no pulses to be felt anywhere, breathing was impaired and was being assisted, the pupils were dilated and not reacting to light, and indeed the only definite evidence of life was an ECG trace on the oscilloscope. These features if fuund in the field would probably lead to a diagnosis of death. It is therefore encouraging that the patient survived and even-

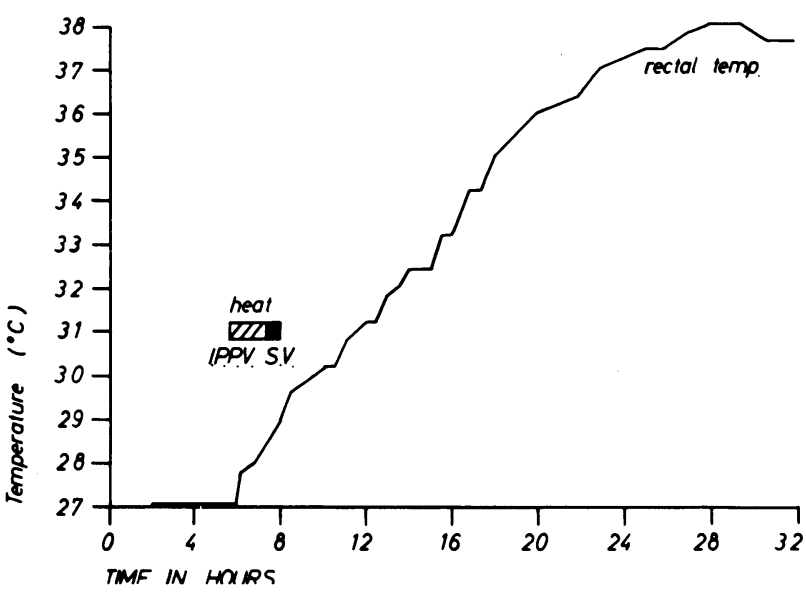
tually returned to work.

A warm humidified atmosphere can be provided in a number of ways but the method at present being used is to utilise the interaction of carbon dioxide and anaesthetic soda lime which by chemical means produces heat and moisture. The patient then breathes through the hot moist soda lime. This is in fact the system which was used for the human cases treated in hospital and portable equipment is being developed (Lloyd et. al., 1972; Lloyd, 1973; Bell, 1975).

When hypothermia occurs in the field monitoring is difficult for obvious reasons. The two cases so far treated by this method (Lloyd and Frankland, 1974; Bell, 1975) have been rewarmed successfully when found. The only conclusion possible is that further field trials are justified.
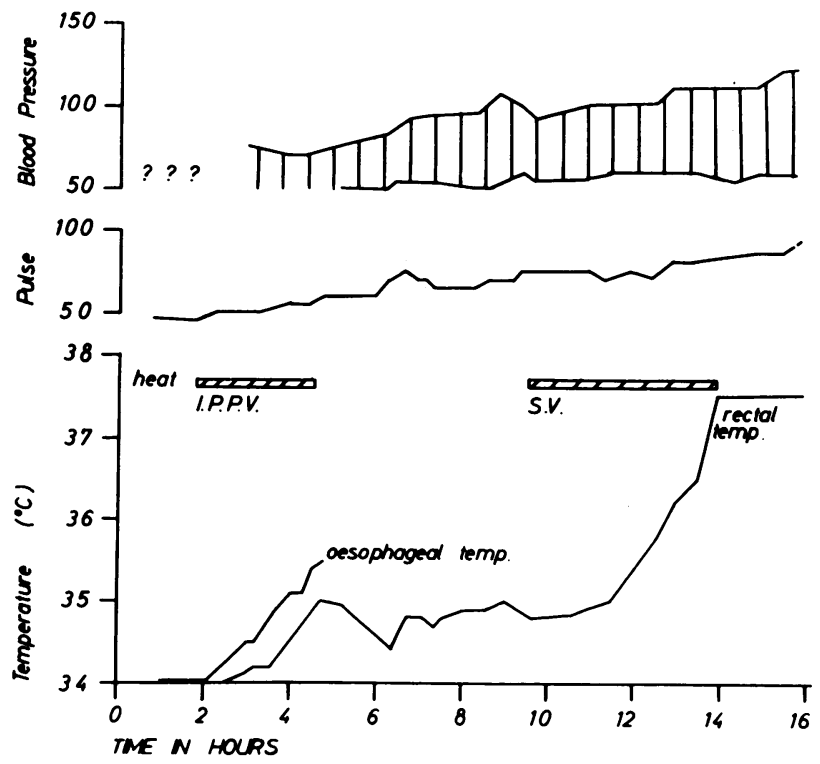


\section{REFERENCES}

BELL, P. M. (1975) Personal Communication.

BIGELOW, W. E., LINDSAY, W. K., HARRISON, R. C., GORDON, A., GREENWOOD, W. F. (1950) Oxygen transport and utilisation in dogs at low body temperature. Ann.J.Physiol. 160: 125.

BURTON, A. C. and EDHOLM, O. G. (1955) Man in a cold environment. Edward Arnold Ltd., London.

DUGUID, H., SIMPSON, R. G., and STOWERS, J. M. (1961) Accidental hypothermia. Lancet 2: 1213.

EDHOLM, O. G. and BACHARACH, A. L. (1965) Exploration medicine, John Wright and Sons Ltd., Bristol.

FREEMAN, J. and PUGH, L. G. C. E. (1969) Hypothermia in mountain accidents. Int.Anaesth.Clin. 7: 997.

KEATINGE, W. R. (1969) Survival in cold water. Blackwell, Oxford.

LLOYD, E. L., CONLIFFE, N. A., ORGEL, H., WALKER, P. N. (1972) Accidental hypothermia: an apparatus for central rewarming as a first-aid measure. Scot.med.J. 17: 83.

LLOYD, E. L. (1973) Accidental hypothermia: treated by central rewarming through the airway. Brit.J.Anaesth. 45: 41.

LLOYD, E. L. and FRANKLAND, J. C. (1974) Accidental hypothermia: central rewarming in the field. Br.Med.J. 4: 717.

LLOYD, E. L., MITCHELL, B. and WILLIAMS, J. T. In preparation.

TAYLOR, D. E. M. (1972) Cold survival. Br.J.Spt.Med. 6: 111. 